\title{
ISOLATION HOSPITALS FROM THE POINT OF VIEW OF THE MEDICAL OFFICER OF HEALTH.
}

\author{
By D. S. IMTIES, M.U., D.P.I., \\ Medical Officer of Health, Bristol. \\ Read at Sessional Meeting, Bristol, April 8th, 1905.
}

\begin{abstract}
ATHOUGH Bristol is the sixth largest town in England, it is not A yet adequately provided with isolation hospital accommodation. This is not to be ascribed to the neglect of the Health Committee, for they have been placed, erer since their formation in 1897, in a peculiarly onerous position. Most, if not all of the large towns had, many years bofore that time, commenced to make provision of this sort, and over a series of years have completed their schemes up to at least the minimum of one bed per 1,000 population. The reason why Bristol lagged hehind was that, through the complaisance of the Guardians, the omus of dealing with epidemic disease still resterl upon them until 1894, when they revolted. Thereupon seventy-six permanent beds at Ham Green and a small (stablishment at Nover's Hill, mustly temporary, arose by 189!; but meantime the city population had increased by over 100,000 persons, and thus the arailable beds, even with the addition of twenty-two beds (temporary) for diphtheria at Clift House, became quite inadequate, and in no way replaced the accommodation formerly afforded by the Guardians.

Towards supplying some of this deficiency the new block, which is to be inspected by the members, has been supplied as a substantial instalment.
\end{abstract}

\section{Isolation Hospitals : The Theory aNd Practice of their EFfective Use.}

The temporary seclusion of a person suffering from a communicable fever which comes to a definite end in a short period (acute), should 
succed in preventing any further spreat of the disense in question, provided the following "essential comlitions" are fulfilled:-

1. The patient has not handed on his infection to aly other person before his seclusion commenced.

2. The patient has left hehind no infected material, or, if he has, such infected material is rendered sterile.

3. The patient is kept perfectly secluded, through the whole of his illness and convalescence, from direct or indirect communication of his disease to others.

4. The patient perfectly recovers before he is cleansed and discharged from sechusion.

Failure in any one of these essential conditions mav wreck the preventive success of isolation, but this does not affect the value of isolation as a principle.

Let us consider some factors influencing the fulfilment or failure of the four essential conditions of isolation.

\section{Tine Natural Histoli of the Diseane in Question.}

The spread of our common communicable fevers may be taken to be, with perhaps the exception of enteric fever, immediately personal. Discase spreading in this way from person to person tends to assume, if unchecked, a geometrical rate of increase, so that one case may, with a common ratio of three, give rise in five incubation periorls to some 240 cases. This effect is most clearly seen, as is also the simple inhiliting effect of complete isolation, in a disease which between its periods of invasion disappears utterly from amongest a population. Upon its reintroduction as a single case it is thus often possible to watch the progress of epiclemic growth from this one case, and to realise, in checking the first outgrowths, the real meaning of "preventive" medicine. Epidemics are never ready-made. Smallpox is a trpe of disease that notably grives us this opportunity, by reason of the life-habits of its causal parasitic organism. This is so highly organised that it is selective in regard to the soil on which it grows, and will neither grow on an unsuitable nor an exhausted soil. Also we can render the soil of contacts unsuitable by inducing vaccinia. If the soil is unsuitable the person exposed to infection neither contracts smallpox nor carries it; the infection simply dies out. Again, if the soil is suitable the disease runs its acute course; after which the soil becomes exhausted, and the disease cannot, and never does, persist in the patient. So we get no chronic cases and no "return" cases. 


\section{Isolution Hospilals from the M.O.II.'s Point of Vien.}

Hence we may say that a patient either definitely has or has not smallpox at any particular time; he never merely rarries it on his livingr tissues in an inert, but to others a potentially infective, form.

A gain, the disease, although one of high infectivity, is not so except to intimate contacts, for the first two days.

Owing to these points in its natural history smallpox is the most straightforward of discases, and in general, when taken in land upon its first introduction, all four of the essential conclitions of isolation may be reatlily fulfilled. Ilence hospital isolation is generally successful in this lisease, and its methods and value can be usefully clemonstrated.

I do not think I need labour this point, as the value of hospital isolation as our essential in dealing with the spreat of smallpox is generally arlmitted.

Diphtheria is a clisease whose nitural history renders it much less straightforward thin smallpox, although it resembles that disease in being spread from person to person.

The parasitic fungus of diphtheria appears, however, to be more lowly organised; it is certainly not selective as to its soil. Most or all soils prove suitable; it will grow in some form or other upon the mncous surfaces: palatal, nasal, aural, \&c., or ulon raw skin surfaces of, probably ninetenths of all children under 12, and somewhat less freely upon older persons. Of these nine-tentlis who receive the organism, retain and grow it (i.e., become infected), only about half are susceptible to intoxication by the fungus (i.e., suffer from clinical diphtheria): while the remaincler. carry it merely, showing no symptoms, or very slight symptoms themselves, but being potentially highly infections to others.

Further, an exhausted soil forms no bar to further growth: the patient who has passed through the clinical disease recover's, but the fungus, though it can larm him no further may continue to flourish just the same, having perehance gained access to the recesses of the nasal cavity, to the antrum or to the frontal sinuses.

Hence we are confronted with an acute infertions disease, which may upon occasion, fortunately not of ten, become chronic and may persist for months or years. And again, we are confronted with a disease in regard to which a patient may present one of three conditions: he may be (1) suffering from it; (2) not suffering from it; (3) carrying it.

It is obvious that such a disense as diphtherial presents far more complicated problems to solve than does smallpox.

For example, when a case of clinical diphtheria is notified, we cannot be satisfied with mere removal of the obvious patient and the usual 
disinfection. The patient may be only one of several home cases, the symptoms in the others having been masked or absent; and all home contacts need to be bacteriologically examined before we can satisfy condition (1) of success in isolation.

Isolation in cliphtheria is most necessary for securing the full use of antitoxin, and for operative treatment of laryngeal cases. Judiciously used, removal of undoubted cases, together with home prophylactic treatment of suspicious cases has a marked effect, though a limited one, in cherking the spread of this discase.

Scarlet fever is more akin to diphtheria than to smallpox in the difficulties it presents to successful isolation; but the tendency to chronicity is much less markerl, and I think of less duration than in diphtheria. Scarlet fever is prone to assume extremely mild types, especially of late years, and these cases are readily "missed," and keep the infection going. Hospital isolation can obriously not deal with "missel" cases, and therefore fails to control a certain amount of the spread of the disease. The extreme mildness of scarlet fever nowadays has rendered the detection of cases increasingly difficult; the mildness of the epidemic form therefore is responsible very largely for increased spread of this disease of recent years.

The Amount of Honpital Accommodation Necessary, and the Methods of it's use. Tilf Need fol Anticipatory Provision.

Possibly no more difficult point exists. The minimum isolation hospital provision for large towns is accepted at one bed per 1,000 of the population. The cubic space per bed should be at least 2,000 feet. How can this be allotted to the various diseases?

Smallpox.-The amount needed depends intimately upon the district, its exposure to introductions, and upon the personal element and experience used in the medical control of introductions. For example, our reserve bels for a possible smallpox introduction are twelve only, and we have thirty-five beds, without overcrowding, for smallpox altogether; this is, of course, not enough; the reserve alone at Newcastle-on-Tyne amounts to 100 beds. But the penalty of ten years' unbroken success in dealing with introductions in Bristol has to be paid, although the city, in 1897 and last year, was increased by a greater number of persons than the whole city of Birkenhead or of Southampton. Well-nous rerrons. - it is possible that a variant of the fable of the Shepherd and the Wolf might occur, wherein the shepherd warded off real wolves, with what help he had, until a day came when the wolves prevailed. 


\section{Isolation Hospitals from the M.O.II.'s Point of Ticw.}

Provision should be anticipatory.

Beds are often most useful uhen generally ompty.

These are the most difficult points for the lay mind to grasp, and yet they lie at the root of efficiency. The twelve vacant becls have clone yeoman service with introductions of smallpox, which, for example, came in during six months of 1903 at an average of one case every fortnight.

If these twelve beds had not been waiting, in a very few weeks 100 beds would not have sufficed, for epidemics spring from single cases.

With scarlet ferer we are never, in a large city, in the same position of vantage as with smallpox. It is endemic, never absent for a single day, characterised only by periodical, so-called epidemic exacerbations and remissions, and by occasional outbreaks due to school influence or to some other special cause, such as the chance infection of a milk supply.

Is the attempt at isolation of any use in controlling the spread of this disease?

This is a question frequently asked, and attempts have been made to answer it in many ways, notably, (a) by appeal to comparative statistics of different districts, and (b) by appeal to comparative statistics of the same district at different periods.

(a) This method is fallacious for many reasons. Districts approach isolation from different standpoints: in one district cases will be moved indiscriminately as they apply; in another district careful selection will be made, and only those cases that cannot be properly isolated at home will be moved to lospital.

For the indiscriminate method an excess of accommorlation is needed, as in Liverpool, where there are, I believe, 1,200 beds available for 700,000 population. This system seems to me to aim at relief rather than isolation, and to save trouble to many parents who are perfectly well able to carry out isolation themselves. 'Towns with more modest accommodation, not exceeding one bed per 1,000 of the population, must needs discriminate their cases or the hospitals will become full very soon on an epidemic wave, and a full isolation hospital is a sign of failure. The constitution of the population of different towns varies also as to age distribution, occupation, school habits, exposure to imported infection; and further, for any useful comparison, two periods should be chosen presenting the same period of attack by epidemic wares of similar intensity, and by a strain of disease of similar kind.

(b) Nor do comparative statistics of the same district at different periods always prove conclusive, for we must accept the fact that the 
strain of disease introduced in different epidemics varies enormously, and we cannot confidently predict from the action of a certain clisease in one epidemic its action in the next. From our own experience in Bristol I am umable to draw any conclusions, partly because we have never yet had sufficient hospital accommodation to isolate all the cases that needed it, and partly because the enormous growth of the city in 1897 added a new population of some 100,000 persons to the city, and so rendered comparison with previous conditions impossible. It is true that in 1899 the first instalment of fever beds was opened at $\mathrm{Ham}$ Green, but this amounted to seventy-six beds (or one hundred with crowding), and was inadequate to the minimum needs even of the old city.

Since notification commenced in 1890 , three epidemic periods of scarlet fever have occurred; two are comparable, viz., the 1892-3, and the 1896 epidemic-the latter showing a lower prevalence figure and shorter duration. The next epidemic wave, however, involved the extended city, and so is not in any way comparable; it has shown high prevalence figures over a long period, but quite low mortality. And this low mortality is of course due to the mild strain of disease, with a fatality not exceeding $2 \cdot 4$ per cent. in any one year : true, but so also is the wide prevalence due to the mild strain of disease. This is a point that is generally neglected, but most health officers will agree with me that if every single case in an epidemic of any lisease was always well marked and clinically serious, it would be a good thing for the community. Recognition would be easy, isolation could be made effectual, and the disease would be readily controlled. "Missed" cases are amongst the most effectual promoting causes of an epidemic, and mild outbreaks are therefore by far the most difficult to meet, and the most dangerous to the community; in addition, they serve to veil the undoubted utility of isolation hospitals.

The answer to the question, How much hospital accommodation is needed! may rary considerably with the type of disease.

For example, I have now had nineteen years' experience in this city; for the first thirteen years I neither liad, nor felt the want of, beds for cases of diphtheria, which was not very fatal (the mortality varying from a half to a quarter that for England and Wales), never caused school outbreaks, and showed little tendency to spread, or to linger in "carrier" cases. Suddenly in February, 1900, all this was changed. Bedminsier, a southern district of the city, was invaded, apparently from the county, by a virulent form of bacillus, which attracted our attention in the laboratory as morphologically distinct from the forms we were accustomed to.

In cpidemic virulence and fatality it corresponded, and for the past 


\section{$25+$ Isolution Hospitals from the M.O.H.'s Point of View.}

five years we have shared the fate of many towns in an unequal contest with this most insidious and difficult form of diphtheria, which is fatal, causes school outbreaks, and affects whole families in throat, or nose, or ears; it also produces severe, or moderately mild, and "carrier" cases amongst groups of contacts, and is persistent and sometimes distinctly chronic. For this we have needed sometimes as many as eighty heds; and its prevalence has still further lessened the amount of scarlet fever accommodation available. The added districts have proved by far the most susceptible to diphtheria, for some two years they furnished the bulk of the cases. The whole course of the outlyreak has tended to confirm my belief that the spread of diphtheria is a purely personal matter, and that in an ordinarily well-looked after town at any rate insanitary conditions arc inoperative. The diphtheria bacillus is much too delicate an organism to live in drains or on filth heaps: and the sum of the effect that even a rampant insanitary conclition can reach would be, I suspect, to produce a somewhat susceptible mucous surface for the implantation of the specific fungrus received from another person. Insanitary conditions are unlovely, and must be amended; but I do not know that they bear any causal relationship to the ordinary communicable ferers of this country, with the exception, of course, of the intestinal disease, typhoid ferer.

[For Discussion on this Puper, see prage :60.] 